\title{
ENDÜSTRİ 4.0'A BÜTÜNCÜL BİR YAKLAŞIM: ÖRNEK OLAY ANALİZİ VE STRATEJİK YOL HARİTASI
}

\author{
Ömür Neczan tímURCANDAY ÖZMEN* , Engin Deniz ERİş**, \\ Pınar SÜRAL ÖZER ${ }^{* * *}$, Hasan ZEREY****
}

öz

Yazında son dönemde farklı disiplinlerde ele alınan Endüstri 4.0 uygulamalarına ilişkin olarak farklı boyutlarla Endüstri 4.0'a hazır olma ve olgunluk şeklinde ifade edilen modeller bulunmakla birlikte daha bütüncül bir sorgulamaya da gereksinim duyulduğu fark edilmiştir. Bu farkındalıktan hareketle amaca yönelik olarak seçilen ve imalat endüstrisinde uluslararası platformda faaliyet gösteren örnek işletmede Endüstri 4.0 sürecini destekleyecek örgütsel bir ortamın oluşumunu kolaylaştıracak örgütsel ve bireysel özellikleri incelenmek üzere durum çalışması gerçekleştirilmiştir. Bütüncül tek durum deseni ile yapılandırılan çalışmada nicel ve nitel yöntemler kullanılarak üçleme yapılmıştır. Üç adımdan oluşan araştırma sonucunda işletmenin Endüstri 4.0 sürecindeki konumu analiz edilirken örnek işletmeden hareketle uygulamacılar için öneriler sunulmuştur.

Anahtar Sözcükler: Endüstri 4.0, Strateji, Endüstri 4.0 Hazırlık Modeli, Örgüt Kültürü, Kişilik, Yetkinlik, Teknolojiye Hazırlık

\section{A HOLISTIC APPROACH TO INDUSTRY 4.0: CASE ANALYSIS AND STRATEGIC ROAD MAP}

\section{ABSTRACT}

In the literature, although there are models expressed in the form of maturity and readiness for Industry 4.0 with different dimensions regarding the applications of Industry 4.0, which have been dealt with in different disciplines, but a more holistic examination is needed. Based on this awareness, a case study was carried out to examine the organizational and individual characteristics that will facilitate the formation of an organizational environment that will support the Industry 4.0 process in a sample enterprise selected for the purpose and

\footnotetext{
*Dokuz Eylül Üniversitesi, İşletme Fakültesi, İşletme Bölümü, İzmir, E-posta: omur.ozmen@deu.edu.tr

(iD) https://orcid.org/0000-0002-3379-317X

${ }^{* *}$ Dokuz Eylül Üniversitesi, İzmir Meslek Yüksekokulu, İzmir, E-posta: engindeniz.eris@deu.edu.tr

iD https://orcid.org/0000-0002-0652-3975

${ }^{* * *}$ Dokuz Eylül Üniversitesi, İktisadi ve İdari Bilimler Fakültesi, İşletme Bölümü, İzmir, Eposta: pinar.ozer@deu.edu.tr

${ }^{* * * *}$ Dikkan Group TalaşıI İmalat Müdürü, İzmir, E-posta: zereyhasan@hotmail.com
} 


\section{Ömür Neczan Timurcanday Özmen, Engin Deniz Eriş, Pınar Süral Özer ve Hasan Zerey}

operating in the international platform of manufacturing industry. In the study, which was structured with a holistic single case design, triangulation made by using quantitative and qualitative methods. As a result of the three-step research, the position of the company in the Industry 4.0 process was analyzed and recommendations were made for the practitioners based on the sample enterprise.

Keywords: Industry 4.0, Strategy, Industry 4.0 Readiness Model, Organizational Culture, Personality, Competency, Technology Readiness

\section{GİRİş}

İşletmeler günümüzün yoğun rekabet ortamında artan tehditlerle başa çıkmanın yollarını bulma konusunda daha da fazla çaba göstermek zorunda kalmaktadırlar. İnovasyon becerisi ve pazara hızla girme vazgeçilmez uygulamalar olarak görülürken tüketici beklentileri ve talepleri de her geçen gün değişmekte ve yeni uygulamalara olan gereksinim daha da artmaktadır. Bu noktada değişen koşullara uyum konusunda gereken esnekliği yaratabilecek akıllı imalat sistemleri geliştirilmeye çalışılmakta, basit ve rutin işler kadar karmaşık ve yüksek beceri ve yetkinlik gerektiren işler de dijitalleştirilmektedir. Genel itibari ile Endüstri 4.0, makinelerin bilgisayarlar ve internet teknolojilerindeki yeni gelişmeler sayesinde uyumlanabilir hale gelmesi, üretim kapasite ve yöntemlerinde ileri seviye teknolojiye geçilerek fabrikaların kendini yönetebilir olmasını ifade etmektedir.

Önceki yüzyıllara oranla çok daha hızlı teknolojik yenilenmenin ve değişimin yaşandığı yeni yüzyılda ilk devrim fakat işletmecilik açısından dördüncü devrim olarak karşımıza çıkan Endüstri 4.0, işletmeler için rekabetçi ortamın daha da zorlaşması anlamına gelmektedir. Hızla gelişen teknoloji, hızla değişen strateji gereksinimini de beraberinde getirmektedir. Bu dönüşüm içinde hayatta kalabilmenin yolu olarak Endüstri 4.0'ın gereklerine uyum sağlayabilmek esas olmaktadır. Özellikle imalat sektöründeki değişen teknolojilere uyum konusunda işletmelerin gerçekleştirmeleri gereken örgütsel ve bireysel düzeydeki faaliyetlerin etkin biçimde düzenlenmesi gerekmektedir. Ancak bu bağlamda işletmelerin hangi örgütsel ve bireysel özellikleri dikkate alarak dönüşme uyum sağlamaları gerektiği de uygulamacılar tarafından sıklıkla sorulan bir sorudur. 


\section{Endüstri 4.0'a Bütüncül Bir Yaklaşım: Örnek Olay Analizi ve Stratejik Yol Haritası}

\section{SORUNSAL VE ARAŞTIRMANIN AMACI}

Verimli, esnek ve kişiselleştirilmiş üretimi esas alan ve bunu yetkinin göçerildiği dijital üretim kontrolü ve yeni değer zinciri yapılanması ile sağlamayı amaçlayan Endüstri 4.0 dönüşümünü gerçekleştirmek isteyen işletmelerin bu süreçte pek çok sorunla karşılaştığı akademik ve uygulamaya dayalı kaynaklarda belirtilmektedir (Lee ve Benjamin, 2018; Pessl, Sorko ve Mayer, 2017; Mohelska ve Sokolova, 2018).

Araştırmalar, işletmelerin, Endüstri 4.0'ın felsefesi ve temel kavramlarını henüz tam olarak anlamadıklarını göstermektedir (Rajnai ve Kocsis, 2018; Sony ve Naik, 2019; Stentoft, Wickstrøm, Kristian ve Anders, 2019; Ślusarczyk, 2018). Bir yandan Endüstri 4.0'ı işletme stratejileri ile ilişkilendirmekte ve yeni stratejiler geliştirmekte güçlük yaşarken öte yandan, Endüstri 4.0 vizyonu ile ilgili hazırlık ve gelişme durumunu belirlemede problemle karşılaşmakta, bu yüzden somut eylem planları, program ve projelerini belirlemede başarısız olmaktadırlar. Bunun nedeni ise Endüstri 4.0 ve ilişkili kavramların geniş bir çerçeveye yayılması ve karmaşık olmasıdır (Erol, Schumacher ve Sihn, 2016). Akademik yazın açısından da açık ve ortak bir anlayışa henüz ulaşılamamıştır, kavramlar hem uygulamacılar hem de akademisyenler açısından muğlaktır (Hofmann ve Rüsch, 2017).

Endüstri 4.0 fikri ile ilgili belirsizlikle başa çıkabilmek için işletme stratejileri ve işlemlerini planlamalarını destekleyecek iyi bir rehbere ve yenilikçi bir ortama gereksinim duyulmaktadır. Alan yazın çalışmalarının çoğu konunun teknik yönünü ele almakta ancak başarıyı etkileyen temel faktör olan örgütsel ve bireysel faktörlere çok az değinilmektedir (Mohelska ve Sokolova, 2018).

Bu çalışmanın ana sorunsalı da bu gereksinim ve eksiklikten yola çıkarak, Endüstri 4.0 dönüşümünde işletmelerin başarısında stratejik önemi olduğu düşünülen faktörlere bütüncül bir bakış açısı ile yaklaşmaktır.

Sorunsala dayalı olarak araştırmanın amacı, Endüstri 4.0 sürecini başlattığını ifade eden bir işletmenin halihazırdaki durumunu analiz etmek ve devamında da mevcut modellerde üzerinde fazla durulmayan sosyal yapıya ilişkin örgütsel ve bireysel boyutları da kapsayacak biçimde, stratejik bir yol haritası ortaya koymaktır. Bu amaca yönelik olarak da çalışma iki ana soruya yanıt aramaktadır:

1. Çalışmanın örneğini oluşturan işletme, Endüstri 4.0 sürecinin neresindedir? 


\section{Ömür Neczan Timurcanday Özmen, Engin Deniz Eriş, Pınar Süral Özer ve Hasan Zerey}

2. Çalışmanın örneğini oluşturan işletme, Endüstri 4.0 sürecinin başarı ile uygulanabilmesini destekleyecek örgütsel ve bireysel boyutlar açısından hangi özellikleri taşımaktadır?

Bu noktadan hareketle de böylesi bütüncül bir yaklaşım ile Endüstri 4.0 sürecinin daha önce incelenmemiş olması çalışmanın özgün yanını oluşturmaktadır.

\section{KAVRAMSAL ÇERÇEVE}

Endüstri 4.0'ın gereği olarak değişen teknolojilere uyum konusunda işletmelerin gerçekleştirmeleri gereken örgütsel ve bireysel düzeydeki faaliyetlerin etkin biçimde düzenlenmesi gerekliliği artık bilinen bir gerçek olarak uygulamacılar ve akademisyenler tarafindan kabul edilmektedir. Ancak Endüstri 4.0 sürecini uygulamaya geçirirken işletmeler, mevcut stratejileri ile dönüşümün gereği olan Endüstri 4.0 kavramlarını (akıllı robotlar vb.) uyumlaştırma konusunda yetersiz kalabilmektedir. Oluşan bu yetersizlik, Endüstri 4.0'ın karmaşık ve kapsamlı temel doğası, stratejik ve operasyonel düzeyde beklenen etkileri ile ilgili farklı algılamalardan kaynaklanabilmektedir (Erol vd., 2016). Bu durumun kaçınılmaz sonucu olarak Endüstri 4.0'a hazırlık yapan işletmelerin dönüşüm için bütünleşik stratejik araç ve yöntemlere gereksinimi de ortaya çıkmaktadır. Bu bağlamda genel olarak örgüt yapısı ile ilgili modeller geliştirilirken diğer taraftan halen önemini yitirmemiş olan insan kaynağı ile ilgili olarak da yetkinliklerin sorgulanması önem arz etmektedir.

\section{Endüstri 4.0 için Ölçüm Araçları}

Alan yazındaki son çalışmalarda Endüstri 4.0'ın yalnızca teknik açıdan değil strateji-örgüt ilişkisi, bireysel özellikler açısından da ele alınmasının gerekliliği belirtilmektedir (Lichtblau Stich, Bertenrath, Blum, Bleider, Millack, Schmitt, Schmitz ve Schröter, 2015). Bu çalışma, bütünleşik bir yaklaşımla bir yandan çok boyutlu olarak Endüstri 4.0 düzeyi, öte yandan örgüt düzeyinde örgüt kültürü ile bireysel düzeyde kişilik özellikleri, teknolojiye hazır olma, Endüstri 4.0'ın gerektirdiği yetkinlikler ile Endüstri 4.0 kavramlarının bilinirlik düzeyi üzerinde durmaktadır.

Endüstri 4.0 dönüşümünde işletmelerin süreç içindeki düzeyini ölçmek üzere yazında ve uygulamada hazırlık düzeyi açısından uluslararası kıyaslama olanağı veren makro boyutta, işletme düzeyinde hazırlık ve olgunluğu ölçen mikro boyutta çeşitli modeller geliştirilmiştir. Mikro modeller incelendiğinde uluslararası yazında IMPULS "Endüstri 4.0 


\section{Endüstri 4.0'a Bütüncül Bir Yaklaşım: Örnek Olay Analizi ve Stratejik Yol Haritası}

Hazırlık Modeli" (https://www.industrie40-readiness.de/?lang=en), Schumacher, Erol ve Sihn (2016)'in "Endüstri 4.0 Olgunluk Modeli", ulusal yazında ise "test4ware - Sanayi 4.0 için Durum Analizi" (Alçin, 2017) öne çıkmaktadır.

IMPULS Vakfı'nın "Endüstri 4.0 Hazırlık Modeli" Almanya Mühendislik Federasyonu, IW Danışmanlık ve RWTH Aachen Üniversitesi Endüstri Mühendisliği Enstitüsü ortak çalışması ile geliştirilmiştir. Bu model, Endüstri 4.0'ın strateji ve örgüt, akıllı fabrikalar, akıllı operasyonlar, akıllı ürünler, veri temelli hizmet ve insangücü boyutlarını içermektedir. İşletmeler bu boyutlar açısından "yeni gelenler", "öğrenenler" ve "liderler" olarak üç düzeyde sınıflandırılmaktadır. Schumacher vd. (2016)'nin "Endüstri 4.0 Olgunluk Modeli" imalat işletmelerinin Endüstri 4.0 vizyonuna ilişkin gelişme durumunu sistematik olarak değerlendirmek üzere bilimsel ve uygulama amaçlı bir model ve ölçme aracıdır. Modelin bilimsel amacl, imalat işletmelerinin mevcut durumu ve potansiyel başarı faktörlerini ortaya çıkarmak için Endüstri 4.0 stratejileri konusunda kesin veri elde etmek; uygulamaya dönük amacı ise işletmenin kendi Endüstri 4.0 olgunluğunu titizlikle değerlendirmesini sağlamaktır. Bu model, strateji, liderlik, müşteri, ürün, faaliyetler, kültür, çalışanlar, yönetişim ve teknoloji boyutlarından oluşmaktadır. Alçin (2017)'in geliştirdiği "test4ware - Sanayi 4.0 için Durum Analizi", ise temel olarak Endüstri 4.0 sürecinin gerektirdiği dört temel yetkinlik alanını tanımlamakta (4ware yaklaşımı - Hardware, Software, Netware ve Wetware) ve bu yetkinlik alanlarında işletmenin durumunu ortaya koymaktadır.

\section{Endüstri 4.0 için Örgütsel ve Bireysel Değişkenlerin Ölçümü}

Yazında Endüstri 4.0'ın değerlendirilmesinde çoğunlukla göz ardı edildiği görülen sosyal yapıya ilişkin örgütsel ve bireysel bileşenler dikkate alındığında ise öncelikle örgüt kültürü ön plana çıkmaktadır. Temel olarak örgüt kültürü işyerindeki davranışlarla yakından ilişkilidir (Mohelska ve Solokova, 2018). Örgüt kültürü, çalışanların davranışlarını ve işlerin yapılış şeklini biçimlendiren değerler, normlar, inançlar, tutumlar ve varsayımlar bütünüdür (Armstrong, 2006). Schein (2004), örgüt kültürünü "bir grubun dışa uyum sağlama ve iç bütünleşme sorunlarını çözmek için oluşturduğu ve geliştirdiği belirli düzendeki temel varsayımlar" olarak tanımlamıştır. Wallach (1983)'a göre örgüt kültürü örgütün misyon, amaç ve stratejilerilerini desteklemelidir. Widyarini (2009) etkili olabilmek için kültürün işletmenin ve çalışanların 


\section{Ömür Neczan Timurcanday Özmen, Engin Deniz Eriş, Pınar Süral Özer ve Hasan Zerey}

gereksinimleri ile örtüşmesi gerektiğini ifade etmiştir. Handoko vd. (2011) çalışan performansını iyileştirmede yaratıcı ve güçlendirici kültür özelliklerine dikkat edilmesi gerektiğini belirtmektedir. Üyelerce benimsenmiş bir örgüt kültürü, örgüt içinde değer, norm ve inançlar vasıtasıyla çalışanları birleştirmekte, birbirlerine güveni ve bağılıılarını sağlayarak, onları örgüt amaçları doğrultusunda harekete geçirmektedir (Kosa, 2011). Bu tanımlardan anlaşılacağı üzere örgüt düzeyinde yapılacak değişimlerde mevcut durumu analiz etme, çalışanların uyumunu sağlamada odaklanılması gereken bir konu olarak kültür, önem arz etmektedir. Cameron ve Quinn (2006)'in geliştirdikleri "Rekabetçi Değerler Yaklaşımı" ise işletme çalışmalarının önemli modellerinden biri olarak kabul edilmektedir. Bu modelde Klan, Adhokrasi, Hiyerarşi ve Pazar olmak üzere dört kültür tipi tanımlamışlardır ve bu dört tip her örgütte farklı düzeylerde bulunmaktadır. Her kültür tipi, baskın örgütsel nitelikler, liderlik stilleri, kaynaştırma mekanizmaları, stratejik önem ortak değerlerini içermektedir. Bu kültür tiplemelerinin temelindeki iki boyut; rekabetçi çevrenin esneklik ve denge isteme derecesi ile örgüt stratejisinin odak ve gücünün içsel ve dışsal olma derecesidir. Adhokrasi (Girişimci) ve Pazar (Rekabetçi), yüksek performanslı ve dışa yönelimli, Klan (Takım/Uzlaşmış) ve Hiyerarşi (Bürokrasi) ise içsel yönelimli kültürlerdir (Deshpandé ve Farley, 2004:5). Klan ve Adhokrasi kültür tiplerinde özgürlük, bilinçli seçim ve içsel bağlılık daha çok vurgulanırken Hiyerarşi ve Pazar kültürlerinde rasyonellik ve amaçların başarılması ön plandadır (Smart ve John, 1996:221). Bu noktadan hareketle Endüstri 4.0'a uyumlu işletmelerde Adhokrasi ve Pazar kültür tiplerinin daha baskın olması beklenmektedir.

Teknik bileşenler her ne kadar Endüstri 4.0'ın temelini oluştursa da insangücünün sağlayacağı katma değer itici güç olarak kabul edilmektedir (Lichtblau vd., 2015). Endüstri 4.0 ile basit ve rutin işlerle birlikte bazı karmaşık işler makinelerle yapılırken, insangücünün daha fazla stratejik, eşgüdümlü ve yenilikçi davranışlar gerektiren görevleri üstlenmek durumunda kalacağı belirtilmektedir (Hecklau, Gaeitzke, Flachs ve Kohl, 2016). Bu nedenle insangücünün önemi ve özellikleri (kişilik, yetkinlik, teknolojiye hazır olma, bilgi düzeyi) dikkate alınması gereken unsurlardır.

Kişilik; bireyin farklı durumlarda ortaya koyduğu davranışları açıklayan, sürekliliği olan, kişilerarası, duygusal, deneyime dayalı etkileşim tarzı olarak tanımlanırken, ölçülmesine yönelik olarak birçok model ve yaklaşım bulunmaktadır. Beş Faktör Kişilik Modeli (John ve Srivastava, 1999) boylamsal ve ampirik çalışmalara dayalı olması, farklı kültür ve 


\section{Endüstri 4.0’a Bütüncül Bir Yaklaşım: Örnek Olay Analizi ve Stratejik Yol Haritası}

gruplarda geçerliliğinin ortaya konması ve psikometrik açıdan kullanımının ve değerlendirilmesinin kolay olması (McCrae ve Costa, 1992) nedeniyle sıklıkla kullanılan bir yaklaşımdır. Modeldeki boyutlar "Dışadönüklük" (enerjik, sosyal olma vb.); "Nevrotiklik" (depresif, sabırsı vb.) "Özdisiplin" (disiplinli olma, görev bilinci vb.); "Yeniliğe Açıklık" (yaratıcılık, değişime açık olma vb.); "Uyumluluk" (hoşgörülü, esnek vb.) şeklindedir (Benet-Martinez ve John, 1998; Bacanlı, İlhan ve Aslan, 2009) ve Endüstri 4.0'da başarılı olabilecek örgütlerde özellikle yeniliğe açık ve uyumluluk kişilik özelliklerine sahip bireylerin çalışıyor olması beklenmektedir.

İşletmelerde bilgisayarların kullanımının yaygınlaşması sonucunda ortaya çıkan 3. Endüstri Devrimi ile yazında bilgisayar kullanım kaygısı olarak başlayan (Davis, 1989; Venkatesh, 2003) ve bilgisayarların ve ilişkili teknolojilerin ilerlemesi ile birlikte kullanıcıların teknolojiye olan tutumları ve algılarını gösteren Teknolojiye Hazır Olma kavramı yazında yer almaya başlamıştır (Parasuraman, 2000). Daha sonra Lin, Shih ve Sher (2007)'nin bireysel farklılıkları da esas alarak Bütünleşik Teknolojiye Hazır Olma Modeli yazında kullanılmaya başlanmışır. Kavramın Türk kültürüne uyarlanması Özer vd. (2013) tarafından yazına kazandırımış ve farklı sektörlerde test edilmiştir. Teknolojiye Hazırlık Modeli, olumlu kapsamda "İyimserlik", "Yenilikçilik" ile olumsuz kapsamda "Güvensizlik", "Huzursuzluk" olmak üzere dört boyuttan oluşmaktadır ve Endüstri 4.0 örgütlerinde çalışacak kişilerin olumlu boyutlardaki özelliklerinin yüksek olması beklenmektedir.

Bir işi yapmada olgunluk, mükemmeliyet olarak tanımlanan yetkinlik (www.tdk.org.tr) işletmelerde verimlilik açısından çalışanlarda sorgulanan önemli bir özelliktir. Endüstri 4.0 açısından gerekli olan yetkinlikler yazında araştırmacılar tarafından farklı model ve boyutlarla ele alınmaktadır (Hecklau vd., 2016 ve 2017; Kleindienst, 2016; Benesonva ve Tuta, 2017; Cotet, Balgiu ve Zalechi, 2017; Prifti, Knigge, Kienegger ve Kremer, 2017). Bu modellerden Hecklau vd. (2016; 2017)'un modeli; Özer, Eriş ve Özmen (2018) tarafından Türk Kültürüne uyarlanmıştır. Dört boyutlu modelde; "Sosyal yetkinlikler" (iletişim, liderlik, kültürlererası beceriler, işbirliği, takım çalışması, ağ becerileri); "Kişisel yetkinlikler" (esneklik, öğrenme isteği); "Metodolojik yetkinlikler" (yaratıclık, girişimcilik, analitik düşünme, sorun çözme becerileri); "Teknik yetkinlikler" (kodlama becerileri, süreç anlayışı) yer almaktadır. İdeal olarak bu yetkinliklerin tamamının Endüstri 4.0 örgütlerindeki çalışanlarda olması beklenmektedir.

Endüstri 4.0 temelde dokuz teknoloji (akıllı robotlar, eklemeli üretim teknolojisi -3D basım-, artırımış gerçeklik, simülasyon, yatay/dikey yazıım 


\section{Ömür Neczan Timurcanday Özmen, Engin Deniz Eriş, Pınar Süral Özer ve Hasan Zerey}

bütünleşmesi, endüstriyel internet -nesnelerin interneti-, bulut, siber güvenlik ve büyük veri analizi) üzerinde yapılanmaktadır. Endüstri 4.0'a dönüşüm sürecinde bu kavramların özellikle beyaz yaka tarafından anlaşıması ve stratejilerin bu kavramların kullanımına yönelik biçimlendirilmesi ama aynı zamanda da mavi yakalıların kavramlara hakim olma ve bu teknolojileri operasyonel boyutta kullanabilmeleri önemlidir.

\section{ARAŞTIRMA TASARIMI}

Araştırma, amaç doğrultusunda durum çalışması olarak tasarlanmıştır. Durum çalışması; belirli bir sistem yapısı içinde o sistemin işleyişine ilişkin ayrıntıları çoklu veri toplama araçları ile ele alma yaklaşımı olarak tanımlanmaktadır (Creswell, 2003; Chmiliar, 2010). Amaç, çoğunlukla daha fazla durumu açıklayabilmek üzere tek bir durumun seçilerek derinlemesine incelenmesidir (Gerring, 2007). Araştırma amacına yönelik olarak ise tek bir analiz biriminden hareketle "bütüncül tek durum deseni" kullanılmışıı (Yin, 1984). Yine araştırma amacına yönelik olarak gereksinim duyulan bilgiyi elde edebilmek üzere amaçlı örneklem (Patton, 1990) tercih edilmiştir. Araştırmada karma yöntem yaklaşımı benimsenmiş olup nitel ve nicel araştırma yöntemleri bir arada kullanılarak üçgenleme yapılmıştır. Denzin (1978)'in tanımlaması ile aynı olguya ilişkin olarak çalışmada karma yöntem açısından nitel ve nicel yöntemlerin bir arada kullanılması olarak adlandırılan üçgenleme / çeşitleme (Jick, 1979), Jack ve Raturi (2006)'nin belirttiği üzere; yönetim çalışmalarında kullanımı ile yorumlama güçlüklerini ve kuram geliştirmede karşılaşılan zorlukların üstesinden gelinmesini kolaylaştırmaktadır. Üçgenleme içinde ise Cresswell (2003)'in tasarımından hareketle "sıralı araştırıcı tasarımı" tercih edilmiştir. Bu kapsamda öncelikle nitel veriler daha sonra nicel veriler toplanarak analiz gerçekleştirilmiştir.

Tablo 1: Araştırmanın Tasarım Basamakları

\begin{tabular}{|l|l|}
\hline Önerilen Araştırma Basamakları & Araştırmada Gerçekleştirilen \\
\hline Araştırma sorularının geliştirilmesi & Sorunsal tespit edildi \\
\hline Araştırmanın alt problemlerinin geliştirilmesi & Sorunsala ilişkin alt sorular belirlendi \\
\hline Analiz biriminin saptanması & İmalat işletmesi seçildi \\
\hline Çalışılacak durumun belirlenmesi & $\begin{array}{l}\text { Endüstri 4.0 düzeyi ve bileşenleri } \\
\text { incelendi }\end{array}$ \\
\hline Araştırmaya katılacak bireylerin seçimi & $\begin{array}{l}\text { Beyaz ve Mavi yaka personel kapsama } \\
\text { alındı }\end{array}$ \\
\hline $\begin{array}{l}\text { Verinin toplanması ve toplanan verinin } \\
\text { önermelerle veya alt problemlerle } \\
\text { ilişkilendirilmesi }\end{array}$ & Sorunsal ile ilişkilendirildi \\
\hline Verinin analiz edilmesi ve yorumlanması & Nitel ve nicel analiz gerçekleştirildi \\
\hline Durum çalışmasının raporlaştırıması & Bildiri ve makale hazırlandı \\
\hline
\end{tabular}




\section{Endüstri 4.0'a Bütüncül Bir Yaklaşım: Örnek Olay Analizi ve Stratejik Yol}

Haritası

Ayrıca Yıldırım ve Şimşek (2008)'in sekiz maddelik araştırmanın tasarımına ilişkin basamaklar dizisi Tablo 1'de görüldüğü üzere göz önünde tutularak araştırma yapılandırılmıştır.

Araştırmanın geçerliliği ve güvenilirliği için Lincoln ve Guba (1985)'nın yaklaşımı benimsenmiştir. Durum çalışmalarında geçerlik ve güvenirlik kavramları yerine inandırıcılık kelimesini öneren araştırmacılar sekiz temel sorunun cevaplanması gerektiğini ifade etmektedir. Tablo 2'de araştırmaya ilişkin inandırıcılığın sorgulanması yer almaktadır. Ancak araştırmanın nicel kısmında da veri toplama aracı olarak kullanılan ölçeklere ilişkin yapı güvenilirlikleri ilerleyen kısımlarda sunulmaktadır.

\section{Tablo 2: Araştırmanın İnandırıcılığı}

\begin{tabular}{|l|c|}
\hline İnandırıcılığa İlişkin Sorgulama & \multicolumn{1}{|c|}{$\begin{array}{c}\text { Araştırmada } \\
\text { Gerçekleştirilen }\end{array}$} \\
\hline Veri kaynaklarıyla uzun süreli çalışıldı mı? & Evet \\
\hline $\begin{array}{l}\text { Çalışma süresince durumla ilgili ortaya çıkan } \\
\text { konular sürekli olarak gözlemlendi mi? }\end{array}$ & Evet \\
\hline Ham veriler kaynaklarıyla kontrol edildi mi? & Evet \\
\hline $\begin{array}{l}\text { Ham verilerin analitik ifadelere dönüşmesine } \\
\text { yetecek kadar çeşitleme yapıldı mı? }\end{array}$ & Evet \\
\hline $\begin{array}{l}\text { Hipotez, değerlendirme ya da oluşan hikâye } \\
\text { analitik ifadelere karşı sistematik olarak test } \\
\text { edildi mi? }\end{array}$ & Kısmen \\
\hline $\begin{array}{l}\text { Araştırmacıdan farklı bir kişi bulguları kontrol } \\
\text { etti mi? }\end{array}$ & Evet \\
\hline $\begin{array}{l}\text { Araştırma raporu okuyucunun bulguların } \\
\text { güvenli olduğuna inanmasını sağlayacak } \\
\text { kadar detaylı mı? }\end{array}$ & Evet \\
\hline $\begin{array}{l}\text { Araştırma raporu yeterli denetim yoluna } \\
\text { sahip mi? }\end{array}$ & Evet \\
\hline
\end{tabular}

Çalışmanın amacı doğrultusunda imalat endüstrisinde uluslararası platformda faaliyet gösteren bir işletme örnek olarak seçilmiştir. Bu işletmenin seçilmesinin ana nedeni; halihazırda Endüstri 4.0'a geçiş sürecinde olmasıdır. İşletme, 1970 'i yıllarda İzmir'de döküm ve vana üretimi konusunda faaliyet göstermeye başlamıştır. Vana üretimi için döküm, işleme ve montaj fabrikalarında güncel teknolojiyi kullanan işletme zaman içinde faaliyetlerini çeşitlendirerek farklı şirketler kurup bünyesine dahil etmiştir. 2010'dan sonra bünyesine eklediği iki şirketle birlikte grup şirketleri olarak anılmaya başlamıştır. Ürünlerini 60'dan fazla ülkeye ihraç eden işletme, kurumsallaşma yolunda kendine hedefler koymuştur. Örgüt yapısında bazı temel işlevleri merkezi olarak yürütürken, üretim birimlerinde lokal intiyaçlara göre belirlemeyi tercih 


\section{Ömür Neczan Timurcanday Özmen, Engin Deniz Eriş, Pınar Süral Özer ve Hasan Zerey}

etmiştir. İşletme bünyesinde mavi (386), beyaz yaka ve yönetici (129) olmak üzere toplamda 515 personel bulunmaktadır.

Üç adımda gerçekleştirilen araştırmanın (Şekil 1) birinci adımı olan doküman analizi aşamasında işletmenin genel faaliyetleri ve Endüstri 4.0'a ilişkin yayınladığı dokümanlar, haberler ile web sayfası analiz edilmiştir. İkinci adımda Endüstri 4.0 faaliyetleri ile doğrudan ilgili üst ve orta yönetim kademesi ile görüşmeler yapılmıştır. Bu görüşmelerde örgütün Endüstri 4.0'a geçiş aşamasında gerçekleştirdiği vizyon, yapı ve faaliyet değişiklikleri sorgulanmıştır. Aynı zamanda "IMPULS Endüstri 4.0 Hazırlık Modeli" ile "test4ware - Sanayi 4.0 için durum analizi" kullanılarak işletmenin Endüstri 4.0 hazırlık düzeyi ölçülmüştür. Birinci modelde strateji ve örgüt, akıllı fabrika, akıllı operasyon, akıllı ürün, veri temelli hizmetler, insangücü olmak üzere altı boyutta işletmenin Endüstri 4.0 uygulamaları incelenmiş ve sektördeki diğer işletmelerle kıyaslama yapılarak konumu belirlenmiş, ikinci modelde ise Hardware, Software, Netware ve Wetware yetkinlik alanlarında işletmenin konumu değerlendirilmiştir.

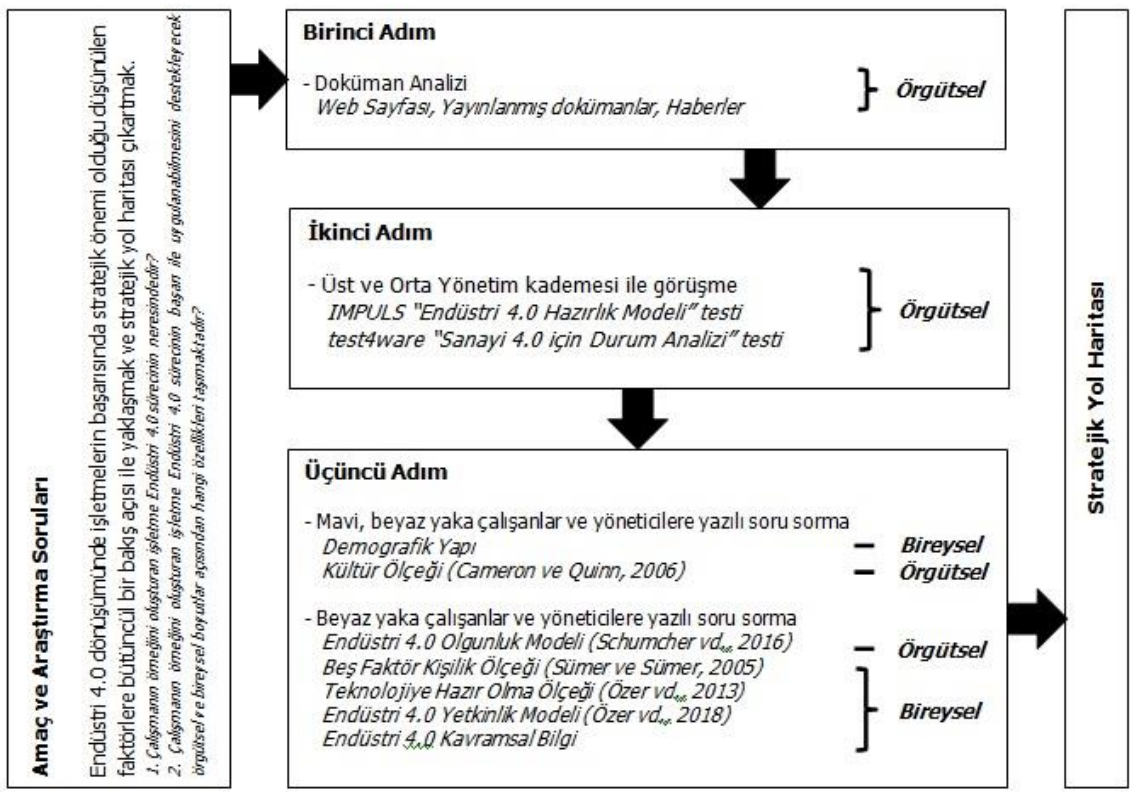

Şekil 1: Araştırmanın Tasarımı 


\section{Endüstri 4.0'a Bütüncül Bir Yaklaşım: Örnek Olay Analizi ve Stratejik Yol Haritası}

Araştırmanın üçüncü adımında ise iki ana kısımdan oluşan soru formu kullanımıştır. Soru formunun birinci kısmını yönetim kadrosu ile birlikte beyaz ve mavi yaka tüm çalışanların cevaplaması istenmiş ve burada örgüt kültürü özellikleri ile demografik yapıya ilişkin veri toplanmıştır. Formun ikinci kısmı ise sadece yönetim kadrosu ve beyaz yaka çalışanlar tarafında yanıtlanmıştır. $\mathrm{Bu}$ kısım beş bölümden oluşmaktadır. Birinci bölüm "Endüstri 4.0 Olgunluk Modeli", ikinci bölüm kişilik özellikleri, üçüncü bölüm teknolojiye hazırlık, dördüncü bölüm Endüstri 4.0'ın gerektirdiği yetenekler, beşinci bölüm Endüstri 4.0 temel kavram bilgisi sorularını içermektedir.

Soru formunun birinci kısmında örgüt kültürünü sorgulamak üzere Cameron ve Quinn (2006) tarafından geliştirilmiş, altı boyut 24 maddeden oluşan Örgütsel Kültür Değerlendirme Aracı dikkate alınarak daha önce Kuş̧̧u (2011) tarafından Türkçeleştirilmiş hali kullanılmıştır. Ayrıca bu kısımda mavi ve beyaz yaka çalışanlarla birlikte yöneticilere ilişkin temel demografik sorular sorulmuştur. Toplamda 323 (231 mavi yaka, 92 beyaz yaka ve yönetici) kişiden geri dönüş alınmıştır (geri dönüş oranı \%63). Bu ölçekteki boyutlara ilişkin elde edilen Cronbach's Alpha değerleri; Hiyerarşi 0,804, Pazar 0,832, Klan 0,833 ve Adhokrasi 0,841 şeklinde iken ölçeğin güvenilirlik değeri 0,913 olarak elde edilmiştir.

Soru formunun ikinci kısmı amaç doğrultusunda toplamda 129 beyaz yakalı çalışan ve yöneticiye form dağıtı Imış ve 92 kişiden yanıt alınmıştır (geri dönüş oranı \%71). Formun bu kısmına ait birinci bölümde Endüstri 4.0 olgunluk durumu Schumacher vd. (2016)'nin geliştirdiği dokuz boyutlu 67 maddeli ölçme aracından yararlanılarak oluşturulan 27 madde ile 5'li Likert Ölçeği ile ölçülmüştür. Ölçekte birinci düzey, Endüstri 4.0 kavramını destekleyecek özelliklerin var olmadığını, beşinci düzey ise gerekli özelliklerin en gelişmiş halinin var olduğunu ifade eden beş olgunluk düzeyini içermektedir. Ölçeğin genel güvenilirliği 0,913 olup ölçekteki boyutlara ilişkin Cronbach Alpha değerleri; Strateji 0,833, Liderlik 0,823, Müşteriler 0,779, Ürün 0,673, Faaliyet 0,749, Kültür 0,796, Çalışanlar 0,804, Yönetişim 0,877, Teknoloji 0,759'dur.

Formun ikinci kısmının ikinci bölümü Benet-Martinez ve John (1998) tarafından geliştirilen, 44 maddeden oluşan Beş Faktör Kişilik Ölçeği'ni içermektedir. Ölçekte "nörotiklik" ve "dışadönüklük" faktörleri 8'er madde, "uyumluluk" ve "özdisiplin" faktörleri 9'ar madde, "gelişime açıklık" faktörü ise 10 madde ile ölçülmektedir. Ölçeğin Türkçe'ye uyarlaması, Schmitt, Allik, McCrae, Benet-Martinez (2007)'in kültürlerarası bağlamda yaptığı çalışmanın Türkiye ayağı kapsamında Sümer ve Sümer 


\section{Ömür Neczan Timurcanday Özmen, Engin Deniz Eriş, Pınar Süral Özer ve Hasan Zerey}

(2005) tarafından gerçekleştirilmiştir. Beş Faktör Kişilik Ölçeği'nin bu çalışmada seçilmesinin nedeni, ölçeğin kültürlerarası bağlamda geçerlik ve güvenilirliğinin test edilmiş olmasıdır. 5'li Likert Ölçeği ile kullanılan bu çalışmadaki ölçeğin güvenilirliğine ilişkin Cronbach's Alpha değeri 0,760 olup boyutlar açısından ise; Dışadönüklük 0,756, Uyumluluk 0,716, Özdisiplin 0,839, Nevrotiklik 0,831, Yeniliğe Açıklık 0,853 şeklindedir.

Üçüncü bölüm; Parasuraman (2000)'ın Teknolojiye Hazırlık Ölçeği'nin Özer, Eriş ve Özmen (2013) tarafından Türk Kültürüne uyarlanmış halinden oluşmaktadır. Bu ölçekte teknolojiye hazır olma durumu 5'li Likert Ölçeği ile dört boyutta (İyimserlik 7 madde, Yenilikçilik 6 madde, Güvensizlik 6 madde ve Huzursuzluk 4 madde) toplam 23 madde ile ölçümlenmiştir. Ölçeğin genel güvenilirlik değeri 0,841 olup boyutlar açısından Cronbach's Alpha değerleri; İyimserlik 0,897, Yenilikçilik 0,785, Güvensizlik 0,817, Huzursuzluk 0,376 şeklinde bulunmuştur. Huzursuzluk boyutunun güvenilirliğinin düşük çıkmasının nedeni, ters ifade olan bir maddenin cevaplayıcılar tarafından anlaşılmaması olabilir.

Dördüncü bölümde insan kaynağı yeteneklerini sorgulamak üzere Hecklau vd. (2016)'nin önerdiği Endüstri 4.0'a hazır olma açısından gerekli olan dört boyutta gruplanan yetenek ve yetkinlikler Özer vd. (2018)'nin Türkiye uyarlaması ile 5'li Likert Ölçeği ile sorgulanmıştır. Ölçeğin genel güvenilirlik değeri 0,900 olup boyutlara ilişkin Cronbach's Alpha değerleri; Sosyal Yetkinlikler 0,792, Kişisel Yetkinlikler 0,767, Metodolojik Yetkinlikler 0,798, Teknik Yetkinlikler için ise 0,458'dir.

Beşinci bölümde ise Industry 4.0 Working Group Report (Kagermann, Wahlster ve Helbig, 2013)'ta belirtilen Endüstri 4.0' oluşturan dokuz temel teknolojiyi ne düzeyde bildikleri $5^{\prime}$ li Likert Ölçeği ile sorgulanmıştır.

\section{VERİLERİN ANALİŻ̇ VE BULGULAR}

Araştırmanın birinci adımı olan doküman analizinde uluslararası platformda faaliyet gösteren işletmenin ulusal ve uluslararası birçok belgelendirme kuruluşu tarafından kalite ve onay belgelerine sahip olduğu, yönetim ve üretim süreçlerini inovasyon ve Ar-Ge yatırımları ile sağlamlaştırmaya çalıştığı ve Endüstri 4.0'a ilişkin işletme politikasına ve yapısal bir modele sahip olduğu görülmektedir. İkincil verilerin analizi sonucunda elde edilen bu sonuç, seçilmiş olan işletmenin Endüstri 4.0 incelemesi için uygun profilde olduğuna ilişkin güçlü bir dayanak sunmaktadır. 


\section{Endüstri 4.0'a Bütüncül Bir Yaklaşım: Örnek Olay Analizi ve Stratejik Yol Haritası}

Araştırmanın ikinci adımı olan üst ve orta kademe yönetici görüşmelerinde öncelikle işletmenin hali hazırda Endüstri 4.0'a geçişte kullandıkları model tartışımış ve işletmenin Endüstri 4.0 karakteri incelenmiştir. Bu model kapsamında olan dört ana boyut; bilişim teknolojileri, strateji, insan kaynakları ile kaynak kullanımı ve müşteri değeri detayları ile tartışımışır. Bu modelin kurgulanmasında ve geliştirilmesinde önemli bir unsur olarak Endüstri 4.0 komitesinin rolü fark edilmiştir. Farklı disiplin ve çalışan düzeylerinden oluşan bu komite, Endüstri 4.0'ın doğasında yer alan disiplinlerarası etkileşim ve uyuma uygundur. Halihazırda bir yapısal model ve Endüstri 4.0 anlayışı hakim olmakla birlikte örgüt yapısında radikal bir değişikliğe gidilmediği, Endüstri 4.0'a uyumlu yeni bölümler ve insan kaynakları açısından yeni pozisyonlar oluşturulmadığı görülmüştür. Yeni teknolojilere yönelik eğitim programlarını içeren uygulamaların da henüz olmadığı, mevcut durumda yönetsel eğitimlerin verildiği belirlenmiştir. Endüstri 4.0'ın doğası gereği çevik hareket edebilmeyi sağlayacak düzeyde yerinden yönetim uygulamaları henüz aktif olarak hayata geçmemiş̧ir. Ancak buradan elde edilen sonuç da işletmenin Endüstri 4.0 incelemesi için uygun profilde olduğuna ilişkin güçü bir dayanak sunmaktadır.

Araştırmanın ikinci adımında daha sonra yöneticiler ile "test4ware Sanayi 4.0 için Durum Analizi" ile "IMPULS Endüstri 4.0 Hazırlık Modeli" kapsamında görüşmeler yapılmıştır. İki modele ilişkin olarak yapılan görüşmeler sonunda elde edilen genel sonuç; işletmenin Endüstri 4.0 düzeyinin başlangıç aşamasında olduğudur. Endüstri 4.0 hazırlık düzeyini ölçmeye yönelik olarak kullanılan birinci model olan "test4ware - Sanayi 4.0 için Durum Analizi" ile elde edilen genel değerlendirme puanı 0,48'dir. $\mathrm{Bu}$ sonuç; işletmenin Endüstri 4.0'ın başlangıcında olduğunu ancak geleceğe hazırlanma konusunda rakiplerden büyük ölçüde ayrışmış olduğunu göstermektedir. Bu model kapsamında yer alan boyutlardan HardWare için puanı 0,42 'dir ve ileride alanındaki liderlerden olacağını işaret etmektedir. NetWare puanının 0,60 olması kurumun kabuğunu kırdığını belirtmektedir. SoftWare puanı 0,52 'dir ve bu sonuç sanal potansiyelinin iyi olduğunu açıklamaktadır. WetWare puanı 0.38 'dir ve insangücünün önemi konusunda işletmenin farkındalığını göstermektedir. Kullanılan ikinci model "IMPULS Endüstri 4.0 Hazırlık Modeli" açısından değerlendirme yapıldığında işletmenin genel puanının 0.38 olduğu görülmektedir. Bu puana göre işletme; "kapıdakiler" olarak isimlendirilen birinci basamaktadır. Benzer işletmelerin 0,31'i de aynı gruptadır. Strateji ve örgüt puanı 0,25 olup birinci basamaktadır ve benzer işletmelerin 0,47 


\section{Ömür Neczan Timurcanday Özmen, Engin Deniz Eriş, Pınar Süral Özer ve Hasan Zerey}

ile aynı grupta yer almaktadır. Akıllı fabrika puanı 0,14'tür ve birinci basamak olarak nitelendirilmektedir. Benzer işletmelerin 0,31'i de aynı gruptadır. Akıllı operasyon puanı 0,10 olup kurumun orta düzey olarak isimlendirilen üçüncü basamakta olduğunu göstermektedir. Benzer işletmelerin 0,42'si aynı gruptadır. Akıllı ürün puanı 0,19 olan kurum birinci basamaktadır. Benzer işletmelerin 0,55'i aynı gruptadır. 0,14 veri temelli hizmet puanı ile kurum birinci basamaktadır ve benzer işletmelerin 0,93'ü aynı grupta yer almaktadır. Son olarak İnsangücü puanı 0,19 ile kurum "başlangıç" düzeyi olarak nitelendirilen ikinci basamakta olup, benzer işletmelerin 0,38'i de aynı gruptadır.

Araştırmanın üçüncü adımında tüm personele (515 kişi) dağıtılan soru formlarından mavi ve beyaz yaka çalışanlar ile yöneticilerden toplamda 323 adet form toplanmıştır (geri dönüş oranı \%63). Toplanan veriler doğrultusunda örgüt kültürü analiz edildiğinde, üyelerin 3,54 ortalama ile "Hiyerarşi", 3,51 ile "Pazar", 3,49 ile "Klan" ve 3,41 ile "Adhokrasi" kültürü olarak algıladıkları görülmektedir. İstatistiksel olarak fabrikalar arasında ise anlamlı bir fark bulunmamıştır. Örgüt kültürü genel olarak "Hiyerarşi" kültürü özellikleri göstermektedir.

Dağııılan soru formlarının ikinci kısmında ise 129 kişilik beyaz yaka çalışan ve yönetim kadrosundan 92 kişi soruları yanıtlamış (geri dönüş oranı \%71) ve elde edilen veriler ışığında değerlendirme yapılmıştır. Şekil 2'de görüldüğü üzere, dokuz boyutlu Endüstri 4.0 Olgunluk Modeli sonuçlarına göre işletme en yüksek oranda kültür $(3,32)$ en düşük oranda ise strateji $(1,96)$ açısından yeterli görülmektedir.

Kişilik özellikleri açısından yapılan değerlendirmede beyaz yaka çalışan ve yöneticilerin sırasıyla özdisiplin $(3,98)$, uyumluluk $(3,66)$, yeniliğe açıklık $(3,57)$, dışadönüklük $(3,51)$ ve nevrotiklik $(2,40)$ özelliklerine sahip oldukları belirlenmiştir.

Örgüt üyelerinin teknolojiye hazır olması açısından yapılan ölçümün sonuçları incelendiğinde; çalışmaya katılanların olumlu boyutlardaki değerlendirmeleri (iyimserlik 4,11; yenilikçilik 3,66 ) olumsuz boyutlardaki değerlendirmelerine (güvensizlik 3,56; huzursuzluk 3,11) göre daha yüksek olmuştur. 


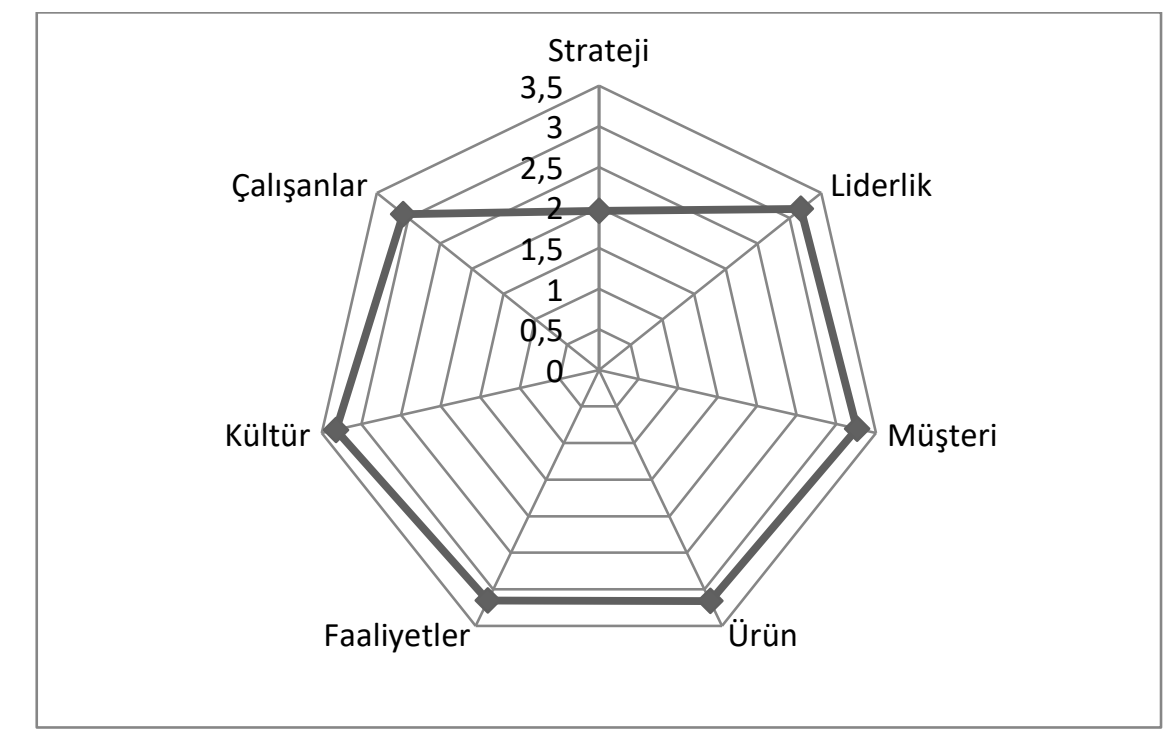

\section{Şekil 2: Endüstri 4.0 Olgunluk Modeli Testi Sonuçları}

Üyelerin Endüstri 4.0 için gerekli görülen yetkinlikleri incelendiğinde; en çok kişisel yetkinliklere $(4,07)$ sahip olduklarını düşündükleri, bunu metodolojik $(4,00)$, sosyal $(3,91)$ ve teknik yetkinliklerin $(3,26)$ izlediği belirlenmiştir.

Üyelerin Endüstri 4.0'ı oluşturan dokuz teknolojiye yönelik kavramsal bilgi düzeylerine ilişkin sonuçlar ise; eklemeli üretim teknolojisinin -3D baskı- $(4,00)$ ile en çok bilinir olduğu, sırasıyla, simülasyon $(3,88)$, akıllı robotlar $(3,72)$, siber güvenlik $(3,70)$, bulut teknolojisi $(3,34)$, büyük veri analizi $(3,14)$, artırılmış gerçeklik $(3,08)$, yatay/dikey yazılım bütünleşmesi $(2,90)$, nesnelerin interneti -endüstriyel internet- $(2,54)$ kavramlarının bilindiği görülmektedir.

\section{TARTIŞMA VE SONUÇ}

Bu çalışmada, Endüstri 4.0 sürecinde olduğunu ifade eden bir işletmede üç adımda gerçekleştirilen araştırma ile sürecin hangi aşamasında olduğu ve başarılı bir dönüşüm için gerekli olan bireysel ve örgütsel özelliklere ne düzeyde sahip olduğu bütünleşik bir yaklaşımla incelenmiştir.

"Çalışmanın örneğini oluşturan işletme, Endüstri 4.0 sürecinin neresindedir?" sorusuna ilişkin İşletmenin Endüstri 4.0 ile ilgili olarak algısının incelendiği birinci (doküman analizi) ve ikinci adımda (yönetici 


\section{Ömür Neczan Timurcanday Özmen, Engin Deniz Eriş, Pınar Süral Özer ve Hasan Zerey}

görüşmeleri), halihazırda geliştirdikleri Endüstri 4.0 modeli, faaliyet gösteren Endüstri 4.0 komitesi ve verdikleri yönetsel eğitimlerle Endüstri 4.0'a geçiş yaptıkları yönünde genel bir sonuç ortaya çıkmıştır.

"test4ware - Sanayi 4.0 için durum analizi" ve "IMPULS Endüstri 4.0 Hazırlık Modeli" kapsamında yapılan değerlendirmelerde işletmenin akıllı operasyon ve insangücü dışındaki boyutlarda başlangıç aşamasında olduğu görülürken, "Endüstri 4.0 Olgunluk Modeli" kapsamında henüz orta düzeyde değerlendirilmiştir.

Araştırmanın "Çalışmanın örneğini oluşturan işletme, Endüstri 4.0 sürecinin başarı ile uygulanabilmesini destekleyecek örgütsel ve bireysel boyutlar açısından hangi özellikleri taşımaktadır?" sorusuna ilişkin yapılan sorgulamada diğer kültür tipleri ile istatistiksel açıdan yakın değere sahip olmakla birlikte göreli olarak baskın çıkan "hiyerarşi" kültürünün Endüstri 4.0'ın içerdiği yenilik, esneklik gibi unsurlar açısından engelleyici bir durum teşkil edebileceği düşünülmektedir. Dolayısı ile Dubkevics ve Barbas (2010)'ın da ifade ettiği üzere yenilikçi bir kültür oluşturmada özellikle Adokrasi ve diğer taraftan Pazar kültürü eğilimlerini öne çıkartacak yönetim yaklaşımlarının benimsenmesi önem arz etmektedir.

Bireysel unsurlardan kişilik özellikleri ele alındığında örgütteki beyaz yaka çalışan ve yöneticilerin "özdisiplin" ve "uyumluluk" kişilik özelliklerinin öne çıktığı görülmüştür. Bu durum örgütün "hiyerarşi kültürü"ne sahip olması ile paralel bir yapı sergilemektedir. Ancak yeniliğe açık olma ve dışa dönüklük özelliklerinin de ortalamanın üzerinde ve diğer özelliklere yakın olması, üyelerin değişim yönetimine hazır olduklarını göstermektedir. Dolayısı ile daha önce Klein vd. (2004)'nin de tartıştığı üzere bu iki kişilik özelliğinin örgütte yenilikçi bir ortam yaratmada kolaylaştıııcı olacağı düşünülmektedir.

Beyaz yaka çalışanların ve yöneticilerin teknolojiye hazır olma konusunda kendilerini iyimser ve ortalamanın üzerinde yenilikçi görmeleri de Endüstri 4.0 dönüşümü açısından olumlu bir sonuç olarak değerlendirilebilir.

Yetkinlikler açısından yapılan değerlendirmede ise beyaz yaka çalışan ve yöneticilerin teknik yetkinliklerinin geliştirilmesi gerektiği ortaya çıkmıştır. Bu kapsamda özellikle Endüstri 4.0 için gerekli olan kodlama becerisi önem arz etmektedir.

Endüstri 4.0'a ilişkin kavramsal bilgi açısından yapılan değerlendirmede özellikle endüstriyel internet -nesnelerin interneti- ve yatay/dikey yazılım bütünleşmesi konusunda eğitim verilmesi gerektiği 


\section{Endüstri 4.0'a Bütüncül Bir Yaklaşım: Örnek Olay Analizi ve Stratejik Yol}

Haritası

fark edilmiştir. Bu sonuç teknik yetkinliklerin geliştirilmesi gerektiği sonucu ile de uyum göstermektedir.

Genel sonuç olarak; işletmenin Endüstri 4.0 sürecinin önemine ilişkin farkındalığının, süreci hayata geçirecek potansiyelinin ve insangücü özelliklerinin iyi olduğu ancak geliştirilmesi gerekliliği ortaya çıkmıştır. Endüstri 4.0 sürecinde olan işletmelerin sosyal yeterlilikler bağlamında örgüt kültürü ve örgütte yer alan çalışanların bireysel özelliklerinin de ele alınmasının gerekliliğine ilişkin genel bir çıkarımda bulunulabilmektedir. Bu bağlamda teknik ve beşeri faktörlerin bir arada bütünleşik bir yaklaşım ile irdelenmiş olması çalışmanın yazına katkısı olarak görülmektedir.

\section{UYGULAMACILAR VE GELECEK ÇALIŞMALAR İÇİN ÖNERİLER}

Endüstri 4.0 uygulamalarında genel stratejiler her işletme için uygun olmayabilir, bu nedenle işletmelerin endüstriyel potansiyelini belirlemek, değerlendirmek ve uygun biçimde kullanabilmek için kendilerine özgü stratejik bir yol haritasına sahip olmaları gerekmektedir. $\mathrm{Bu}$ sürecin etkin biçimde yönetilebilmesi için aşağıdan yukarıya doğru kurumsal bir stratejinin oluşturulması önem arz etmektedir. Bu yaklaşım ile örgüt üyelerinin yeni stratejik yapıyı kabulü kolaylaşırken, kültür de bağlayıcı bir rol oynayacaktır.

Endüstri 4.0 sürecinde yer alan işletmeler, stratejik bir yol haritalarında örgütsel ve bireysel unsurları bir arada ele almalıdır. İşletmenin tüm şirketleri ve bölümleri düzeyinde paydaşların da katılımı ile Endüstri 4.0 stratejisi geliştirilmesi önceliklidir. Yöneticilerle birlikte beyaz ve mavi yaka çalş̧anların öncelikle Endüstri 4.0 konusunda bilgilendirilmesi, hem teknik hem de psikolojik eğitimlerle teknolojiye hazır olmalarının sağlanması, örgüte yeni alınacak üyelerin kişilik özelliklerinin incelenmesi ve özellikle yeniliğe açık ve uyumlu kişilik özelliklerine sahip adayların tercih edilmesi, mevcut çalışanların yetkinlikleri geliştirilirken yeni istihdam edilecek çalışanlarda sosyal becerileri ile birlikte teknik, metodolojik ve analitik yetkinliklerin aranması gerekmektedir. Örgütte Adokrasi ve Pazar kültürlerinin güçlendirilmesi, bütünleşik teknoloji (donanım ve yazıım) ve inovasyon sisteminin geliştirilmesi, tedarikçi ve müşterileri de kapsayacak biçimde entegre bilgi yönetim sisteminin oluşturulması, açık inovasyon stratejileri ile işbirlikleri kurma, IT güvenlik çözümlerinin uygulanacağı alanları belirleme ve kritik bir nokta olarak insangücü - yapay zeka etkileşimini güçlendirilmesi sağlanmalıdır. 


\section{Ömür Neczan Timurcanday Özmen, Engin Deniz Eriş, Pınar Süral Özer ve Hasan Zerey}

Gelecek çalışmalarda bu çalışmada yapılıış olan betimsel analizin dışında Endüstri 4.0'ın uygulanmasında etken olan faktörlerin birbirleri ile olan ilişkileri de ölçümlenmesi, yine Endüstri 4.0 uygulamaları ile ilgili olarak farklı sektörlerde ve farklı ölçekli işletmelerde de ölçüm yapılması, kullanılan modellerin yanı sıra farklı ölçüm araçları ile de yeniden bütünleşik yaklaşım ile ölçümlerin gerçekleştirilmesi önerilmektedir. Endüstri 4.0'ın sadece teknik değil aynı zamanda beşeri özellikleri de göz önünde tutacak şekilde ölçümlenmesi ve uygun stratejilerin belirlenmesinin gerekli olduğu göz önünde tutulmalıdır.

\section{KAYNAKÇA}

Alçin, S. (2017). test4ware - Sanayi 4.0 için durum analizi. https://www.test4ware.net/ (11.11.2018)

Armstrong, M. (2006). A handbook of Human Resource Management Practice $\left(10^{\text {th }}\right.$ ed). London, Philadelphia: Kogan Page.

Bacanlı, H., İlhan, T. ve Aslan, S. (2009). Beş Faktör Kuramına Dayalı Bir Kişilik Ölçeğinin Geliştirilmesi: Sıfatlara Dayalı Kişilik Testi. Türk Eğitim Bilimleri Dergisi, 7(2): 261-279.

Benesova A. ve Tupa J. (2017). Requirements for Education and Qualification Of People in Industry 4.0. Procedia Manufacturing, 11: 2195-2202.

Benet Martinez, V. ve John, O.P. (1998). Los Cinco Grandes across Cultures and Ethnic Groups: Multitrait Multimethod Analyses of the Big Five in Spanish and English. Journal of Personality and Social Psychology, 75(3): 729-750.

Cameron, Kim S. ve Quinn, R.E. (2006). Diagnoising and Changing Organizational Culture Based on the Competing Values Framewok. San Francisco U.S.: Jossey-Bass.

Chmiliar, L. (2010). Multiple Case Design. The Encyclopedia of Case Study Research, A. Mills, G. Durepos, ve E. Wiebe (Editörler), 582584. Thousand Oaks, CA: Sage Publications, Inc.

Cotet, G.B., Balgiu B.A. ve Zalechi V.C. (2017). Assesment Prodecure for the Soft Skills Requested by Industry 4.0. MATEC Web of Conferences, 121: 1-8.

Creswell, J.W. (2003). Research Design: Qualitative, Quantitative, and Mixed Methods Approaches. Thousand Oaks, CA: Sage.

Davis, F.D. (1989). Percieved Usefulness, Percieved Ease of Use, and User Acceptance of Information Technology, MIS Quarterly, 13(3): 319-340. 
Deshpandé, R. ve Farley J.U. (2004). Organizational Culture, Market Orientation, İnnovativeness, and Firm Performance: An İnternational Research Odyssey. International Journal of Research in Marketing, 21: 3-22.

Dubkevics, L. ve Barbars, A. (2010). The Role of Organizational Culture in Human Resource Management. Human Resource Management \& Ergonomics, 4: 1-10.

Erol S., Schumacher A. ve Sihn W. (2016). Strategic Guidance towards Industry 4.0 - A Three-Stage Process Model. Proceeding of International Conference on Competitive Manufacturing 2016 (COMA16), Stellenbosch, South Africa.

Gerring, J. (2007). Case Study Research Principles and Practices. Cambridge: Cambridge University Press.

Handoko, Y., Setiawan, M. ve Surachman, D. (2011). Organizational Culture, Job Satisfaction, Orgaizational Commitment, the Effect on Lecturer Performance. International Journal of Business and Management Invention, 2(12): 21-30.

Hecklau, F., Gaeitzke M., Flachs S. ve Kohl, H. (2016). Holistic Approach for Human Resource Management in Industry 4.0. Procedia CIRP 54: 1-6.

Hecklau, F., Orth, R., Kidshun, F. ve Kohl, H. (2017). Human Resources Management: Meta-Study-Analysis of Future Competences in Industry 4.0. ECMLG $2017 \quad 13 \mathrm{t}^{\mathrm{h}}$ European Conference on Management, Leadership and Governance, 163-174.

Hofmann E. ve Rüsch, M. (2017). Industry 4.0 and the Current Status as Well as Future Prospects on Logistics. Computer in Industry, 89: 23-34.

Jack, E.P. ve Raturi, A.S. (2006). Lessons Learned from Methodological Triangulation in Management Research.Management Research News, 29(6): 345-357.

Jick, T.D. (1979). Mixing Qualitative and Quantitative Methods: Triangulation in Action, Administrative Science Quarterly, 24(4): :602-611.

John O.P. ve Srivastava, S. (1999). The Big Five Trait Taxonomy: History, Measurement and Theoretical Perspective. L.A. Pervin ve O.P. John (Editörler), Handbook of Personality, 102-139. London/NewYork: The Guilford Press.

Kagermann, H., Wahlster, W. ve Helbig, J. (2013). Securing the Future of German Manufacturing Industry: Recommendations for 


\section{Ömür Neczan Timurcanday Özmen, Engin Deniz Eriş, Pınar Süral Özer ve Hasan Zerey}

Implementing the Strategic Initiative Industrie 4.0, Final Report of the Industrie 4.0 Working Group.

Klein, K. Beng-Chong, L. Saltz, J. ve Mayer, D. (2004). How do They Get There? An Examination of the Antecedents of Centrality in Team Networks. Academy of Management Journal, 47:6: 952-963.

Kleindiendst M., Wolf M., Ramsauer C. ve Pammer V. (2016). What Workers in Industry 4.0 Need and What ICT Can Give - An Analysis. $16^{\text {th }}$ International Conference on Knowledge Technologies and Data Driven Business, October 19, Austira.

Kosa, G. (2011). Örgüt Kültürünün Değişiminde İnsan Kaynakları Yönetiminin Rolüne İlişkin Bir Araştırma. Sosyal Bilimler Dergisi, 13(2): 127-148.

Kuşçu, P.Ç. (2011). İş Yeri Zorbalığı ve Örgüt Kültürü İlişkisi Üzerine Sosyolojik Bir Araştırma. Uluslararası Sosyal Araştırmalar Dergisi, 4(19): 371-394.

Lee, B. ve Benjamin, D. (2018). Defining and Assessing İndustry 4.0 Maturity Levels - Case Of The Defence Sector. Production Planning \& Control, 29(12): 1030-1043.

Lichtblau K., Stich V., Bertenrath R., Blum M., Bleider M., Millack A., Schmitt K., Schmitz E. ve Schröter M. (2015). Industrie 4.0 Readıness. This Research Project was Sponsored By Vdma's Impuls-Stiftung Aachen, Cologne, October 2015 Cologne Institute for Economic Research (IW), FIR at RWTH Aachen University https://www.industrie40-readiness.de/?Lang=en (30.11.2018).

Lin, C-H, Shih, H-Y ve Sher, P.J. (2007). Integrating Technology Readiness into Technology Acceptance: The TRAM Model. Psychology and Marketing, 24(7): 641-657.

Lincoln, YS. ve Guba, EG. (1985). Naturalistic Inquiry. Newbury Park, CA: Sage Publications.

Mohelska, H. ve Sokolova, M., (2018). Management Approaches for Industry 4.0: The Organizational Culture Perspective Technological and Economic Development of Economy, 24(6): 2225-2240.

Özer, P.S., Eriş, E.D. ve Özmen, Ö.N.T. (2013). Teknolojiye Hazırlık Düzeyinin Belirlenmesine Yönelik Bir Ölçek Uyarlama Çalışması, İşletme Fakültesi Dergisi, 12(2): 321-333.

Özer, P.S., Eriş, E.D. ve Özmen, Ö.N.T. 2018. Endüstri 4.0: İnsan ve İnsan Kaynakları Yönetimi Neresinde? 26. Ulusal Yönetim ve Organizasyon Kongresi Bildiriler Kitabı, 765-771. 
Parasuraman, A. (2000). Technology Readiness Index (TRI) A MultipleItem Scale to Measure Readiness to Embrace New Technologies. Journal of Service Research, 2(4): 307-320.

Patton, M.Q. (1990). Qualitative Evaluation and Research, Newbury Park, CA: Sage Publications, Inc.

Pessl, E., Sorko, S.R. ve Mayer, B. (2017). Roadmap Industry 4.0 Implementation Guideline for Enterprises. International Journal of Science, Technology and Society. 5(6): 193-202.

Prifiti, L., Knigge M., Kienegger H. ve Kremer, H. (2017). A Competency Model for "İndustrie 4.0" Employees. J.M Leimeister, W. Brenner (Eds.), Proceedings der $13^{\text {th }}$ Internationalen Tagung Conference of Wirtschaftinformatik (WI 2017), St. Gallen, 46-60.

Rajnai, Z. ve Kocsis, I. (2018). Assessing Industry 4.0 Readiness of Enterprises. 2018 IEEE $16^{\text {th }}$ World Symposium on Applied Machine Intelligence and Informatics (SAMI), IEEE, 225-230.

Schein, E.H. (2004). Organizational Culture and Leadership ( $3^{\text {rd }}$ ed). San Francisco: Jossey-Bass.

Schmitt, D.P., Allik, J., McCrae, R.R. ve Benet-Martinez, V. (2007). The Geographic Distribution of Big Five Personality Traits: Patterns and Profiles of Human Self-Description across 56 Nations. Journal of Cross-Cultural Psychology, 38(2): 173-212.

Schumacher A., Erol, S. ve Sihn, W. (2016). A Maturity Model for Assesing Industry 4.0 Readiness and Maturity of Manufacturing Enterprises. Procedia CIRP, 52: 161-166.

Smart, J.C. ve John, E.P. (1996). Organizational Culture and Effectiveness in Higher Education: A Test of the Culture Type and Strong Culture Hypotheses. Educational Evaluation and Policy Analysis, 18(3): 219-241.

Sony, M. ve Naik, S. (2019). Key Ingredients for Evaluating Industry 4.0 Readiness for Organizations: A Literature Review. Benchmarking: An International Journal, Vol. ahead-of-print No. ahead-of-print. https://doi.org/10.1108/BIJ-09-2018-0284.

Stentoft J,. Wickstrøm K,. Kristian J,. Anders Haug P. (2019). Drivers and Barriers for Industry 4.0 Readiness and Practice: A SME Perspective with Empirical Evidence. Proceedings of the $52^{\text {nd }}$ Hawaii International Conference on System Sciences, 5155-5164.

Sümer, N. ve Sümer, H.C. (2005). Beş Faktör Kişilik Özellikleri Ölçeği (Yayınlanmamış çalışma).

Ślusarczyk B. (2018). Industry 4.0 - Are We Ready? Polish Journal Of Management Studies, 17(1): 232-248. 


\section{Ömür Neczan Timurcanday Özmen,, Engin Deniz Eriş, Pınar Süral Özer ve Hasan Zerey}

Venkatesh, V., Morris M.G., Davis, G.B. ve Davis, F.D. (2003). User Acceptance of Information Technology: Toward a Unified View. MIS Quarterly, 27(3): 425-478.

Wallach, E.J. (1983). Individuals and Organizations: The Cultural Match. Training and Development Journal, 12: 28-36.

Widyarini, M.M.N. (2009). Popular Psychology Series: Keys to Self Development. Jakarta: PT Elex Media Komputindo.

Yıldırım, A. ve Şimşek, H. (2008). Sosyal Bilimlerde Nitel Araştırma Yöntemleri. Ankara: Seçkin Yayınevi.

Yin, R.K. (1984). Case Study Research: Design and Methods. Beverly Hills, California: Sage Publications. 